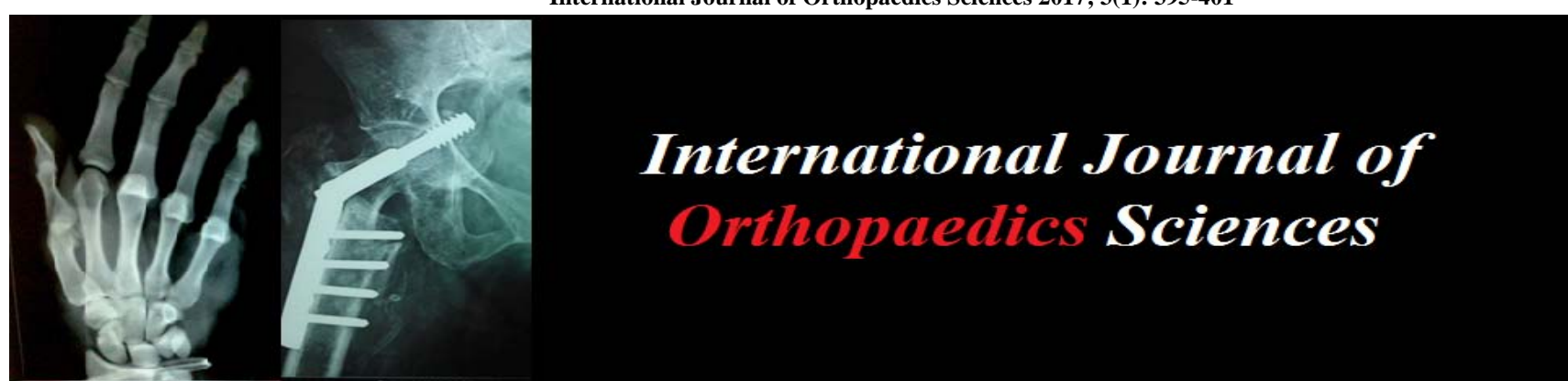

ISSN: 2395-1958

IJOS 2017; 3(1): 395-401

(C) 2017 IJOS

www.orthopaper.com

Received: 18-11-2016

Accepted: 20-12-2016

Dr. Manthan Mandalia

MS Ortho Assistant Professor,

Department of Orthopaedics MK

Shah Medical College

Ahmedabad, Gujarat, India

Dr. Sharvil Gajjar

MS Ortho Chirayu Hospital,

Ahmedabad, Gujarat, India

Dr. Tailor Anand

MS Ortho, Department of

Orthopaedics MK Shah Medical

College Ahmedabad, Gujarat,

India

Dr. Shrey Saxena

MBBS, Department of

Orthopaedics MK Shah Medical

College Ahmedabad, Gujarat,

India

\section{Results of distal end radius volar plating}

\author{
Dr. Manthan Mandalia, Dr. Sharvil Gajjar, Dr. Tailor Anand and \\ Dr. Shrey Saxena
}

DOI: $\underline{\text { http://dx.doi.org/10.22271/ortho.2017.v3.i1f.60 }}$

\section{Abstract}

Background: Fractures of distal end of radius are one of the most common skeletal injuries treated by orthopaedic surgeons. Road traffic accidents are a major cause of fracture in young adults. In elderly fall on outstretched hand becomes a major cause. Road traffic accidents are a major cause of fracture in young adults. In elderly fall on outstretched hand becomes a major cause. For quite a long time, principle treatment of Colles' fracture was forceful traction, manipulation and immobilization of wrist in flexion and ulnar deviation. The extremes of this position (cotton lodor) led to very high incidence of median nerve neuropraxia. The exact position of immobilization and plaster cast extent varied, nevertheless treatment essentially remained same. This study evaluates the results of distal radius fractures (volar barton) treated by open reduction and volar plating.

Materials and Methods: A retrospective study of 40 patients of DISTAL END RADIUS FRACTURES operated with open reduction and internal fixation with volar plate with follow up of at least 6 months. The patients were operated with volar approach and fixation was carried out by AO principles. The patients were mobilized post operatively by active and assisted physiotherapy. Results: The mean age of the patients was 39.27 years with M:F ratio of 7:1. Right side was more involved than the left side and most common cause of injury was fall on an outstretched hand. Most fractures were of Frykman type 7. Post operative assessment was carried out in terms of range of movement, radiological parameters and functional outcomes were assessed in terms of Gartland and Werley scores and PRWE scores.

Discussion and Conclusion: This is a study of 40 patients of distal end of radius fracture treated by volar plating. This study is essentially preliminary assessment. The technique emphasizes that open reduction and internal fixation with volar plating has excellent functional outcome with minimal complications. Hence volar approach and locking plate should be the preferred implant for treatment of intra articular (volar barton), unstable, comminuted fractures of distal end radius.

Keywords: Distal end radius volar plating

\section{Introduction}

Fractures of distal end of radius are one of the most common skeletal injuries treated by orthopaedic surgeons. Three peaks occur in fracture distribution: 5-14 year children, males under 50 year, females above 40 year. In older age group it accounts for $18 \%$ of all fractures due to osteoporosis. Road traffic accidents are a major cause of fracture in young adults. In elderly, fall on outstretched hand becomes a major cause ${ }^{[1,2]}$.

Since first mentioned by Colles in 1814 and though being so prevalent, distal end radius still continues to challenge orthopaedicians ${ }^{[1]}$. Failure to achieve and maintain reduction leads to degenerative arthritis, distal radioulnar and metacarpal instability and ulnar impaction syndrome with resultant pain, decrease in mobility, strength and function ${ }^{3}$.

Optimum results are achieved by understanding the proper fracture pattern and achieving anatomical reduction and early mobilization ${ }^{[3]}$.

The treatment for the diverse spectrum of distal radius fractures relies mainly upon strict definition of specific fracture configuration. Different types of classifications were introduced to explain different fracture configurations to aid in the treatment.

Volar barton injury typically has intra articular fracture displacement with joint subluxation. Hence perfect articular alignment and stability become necessary as recommended by AO.

The extent of displacement of fracture fragment, the degree of articular disruption, the stability and the reducibility of each fracture, as well as any concurrent injury to adjacent neurovascular structures must be assessed carefully in the planning of treatment.
Dr. Sharvil Gajjar

005, Mahadeep Flats, Kalamwadi Society, Near Shreyas Crossing, Paldi, Ahmedabad 380007, Gujarat, India 
Casting and external fixations have been tried but are not able to reduce and/or maintain comminuted/intraarticular distal end radius fractures ${ }^{[4]}$. They had problems of prolonged immobilisation. Casting was associated with swelling and stiffness and inability to treat and maintain comminuted and intraarticular fractures. External fixation addressed some commination but had problems of pin tract infections, tethering of muscle, tendons and capsule, immobilisation and difficulty to reduce and maintain intraarticular fractures.

Open reduction internal fixation with dorsal plating have been tried to address intra articular fractures and above mentioned troubles, with better outcomes but have hardware complications like irritation of tendons and at times even tendon ruptures. Hence volar plating was introduced with ease of lesser dissection per operatively and reduced hardware impingement problems post operatively.

Volar plating provides the benefits of stable anatomical reduction and early mobilization with reduced hardware complications.

This study evaluates the results of distal radius fractures (volar barton) treated by open reduction and volar plating.

\section{AIMS and objectives}

- To evaluate radiological, anatomical and functional outcomes.

- To classify fractures and analyse results according to it.

- To compare our study with other similar studies.

\section{Materials and Methods}

We have done a retrospective study of 40 patients of Distal End Radius Fractures operated with open reduction and internal fixation with volar plate with follow up of atleast 6 months.

\section{Inclusion Criteria}

- Skeletally mature patients.

- Closed fractures

- Injury less than two weeks old

- Comminuted fractures.

\section{Exclusion Criteria}

- Skeletally immature patients

- Open fractures

- Pathological fractures

On admission, patient was first examined thoroughly in Primary survey for vital data and other major associated injuries in head, thorax, abdomen or spine along with local appendicular injuries. Fractures of distal radius were investigated by x-rays and if necessary then a CT scan was carried out for assessment of articular margins.

\section{Definitive Treatment Protocol}

Various treatment modalities and surgical approaches are available for treatment of fractures of distal end of radius.

They are namely:

1. Cast immobilization:

2. External Fixation

3. Percutaneous Pinning and Plaster Immobilization

4. Open reduction and Internal Fixation

We preferred to use the volar approach for open reduction and internal fixation of distal end radius fractures.

\section{Technique used}

- Patient is operated under regional/general anaesthesia.

- Patients were taken on simple radiolucent table with arm rest.
- Antibiotic prophylaxis is administered

- Standard intraoperative Fluoroscopy is used throughout the procedure.

- The whole operative limb is cleaned and draped.

- Tourniquet is applied.

- AO ASIF principles for internal fixation were strictly adhered to:

- Anatomical reduction

- Stable fixation

- Preservation of blood supply

- Early mobilisation.

\section{Surgical Steps}

\section{Step 1}

- Under IITV guidance, traction is given and fracture pattern is assessed.

- One or two k-wires are passed if necessary to hold the fragment.

\section{Step 2: Skin incision}

- Henry's volar approach is used in our study.

- An average $8 \mathrm{~cm}$ incision kept on volar aspect on radial border of flexor carpi radialis tendon and carried along the sheath of the tendon.

- Forearm fascia on the radial side is incised. The index finger is then used to sweep the flexor policis longus ulnarly and pronator quadratus exposed.

- A L-shaped incision is kept on pronator quadratus and small elevator is used to expose the fracture.

\section{Step 3: Selection of Proper size plate}

- Plate length was selected after assessing proximal extent of fracture.

\section{Step 4: Plate placement and screw insertion}

- Fracture reduction is achieved by traction and disimpaction and anatomical alignment of the fracture fragments. Joint is anatomically reduced.

- K-wires are inserted for temporary fixation of fracture fragment.

- Reduction is again reconfirmed under IITV.

- The size 3.5/2.7 volar plate is reconfirmed and put over bone. The central gliding whole screw is inserted after proper positioning of the plate under IITV guidance. Remaining screws were applied under IITV guidance making sure that they do not enter the joint space.

\section{Step 5: Closure}

- Now the pronator quadratus is sutured to cover the plate.

- Subcutaneous and skin closure done over it.

- Post operatively above elbow slabs and pint elevation were given to all patients.

- I.V. antibiotics were continued for first 3 days and then it was shifted to oral till stitch removal.

- I.V. analgesics were given for 1 day followed by oral analgesics when necessary.

- $\quad$ Finger mobilization was encouraged from post op day 2.

- Hospital stay: Patient is discharged as soon as the wound and general condition of the patient is satisfactory, around POD-5.

- Suture removal was done at around two weeks.

- Slabs were continued for four weeks after which mobilization was started gradually.

- Later patients were followed up at monthly intervals when $\mathrm{x}$-rays and clinical outcomes were reviewed and noted. 
- Patients were allowed full activity between three to four months depending upon clinical and radiological union.

\section{Follow up and Outcome}

- Follow up visits were scheduled at 1, 2, 3 and 06 month postoperatively and the clinical and radiological outcomes and any complications were noted.

- Functional criteria of Gartland and Werley score $^{5}$ and PRWE ${ }^{6}$ score used.

- Radiological assessment of Radial inclination, Radial shortening and Palmer tilt were evaluated.

- Range of motion at wrist is compared with normal range given below:

Dorsiflexion: $0^{\circ}-75^{\circ}$

Palmar flexion: $0^{\circ}-80$

Radial deviation: $0^{\circ}-20$

Ulnar deviation: $0^{\circ}-35$

Pronation: $0^{\circ}-70^{\circ}$

Supination: $0^{\circ}-85^{\circ}$

\section{Radiological Assessment}

- Posteroanterior (PA), lateral radiographs of the injured forearm should be obtained.

- Radial height is assessed on the PA view. It is a measurement between 2 parallel lines that are perpendicular to the long axis of the radius. One line is drawn on the articular surface of the radius, and the other is drawn at the tip of the radial styloid. The normal radial height is $9.9-17.3 \mathrm{~mm}$. Comparison with the contralateral normal wrist is recommended if the diagnosis is unclear.

- Ulnar variance (UV) is measured here by using the method of perpendiculars, in which 2 lines are drawn perpendicular to the long axis of the radius. One line is drawn on the ulnar-side articular surface of the radius, and the other is drawn on the ulnar carpal Surface.

- Radial inclination is measured on the PA view; this is a measurement of the radial angle. A line is drawn along the articular surface of the radius perpendicular to the long axis of the radius, and a tangent is drawn from the radial styloid. The normal angle is $15-25^{\circ}$.

- The volar tilt, or palmar inclination, is measured on the lateral view. A line perpendicular to the long axis of the radius is drawn, and a tangent line is drawn along the slope of the dorsal-to-palmar surface of the radius. The normal angle is $10-25^{\circ}$.

\section{Results}

In this study of 40 cases with fracture distal end radius treated by open reduction and internal fixation with volar plating with a minimum follow up of 06 months the observations were made:

\section{Age}

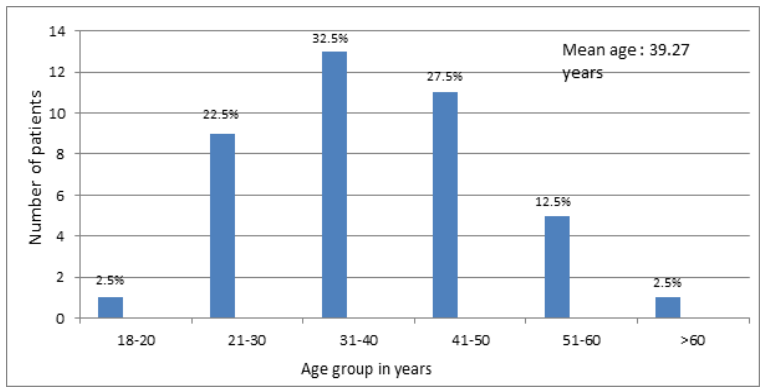

Fig 1: Age distribution
In this study of 40 patients the mean age was: 39.27 year. $34\{85 \%\}$ patients belonged to the age group of $18-50$ years who were relatively young with a reasonable bone stock. This series included only comminuted fractures which required high impact trauma and so the incidence of young patients was higher.

\section{Gender}

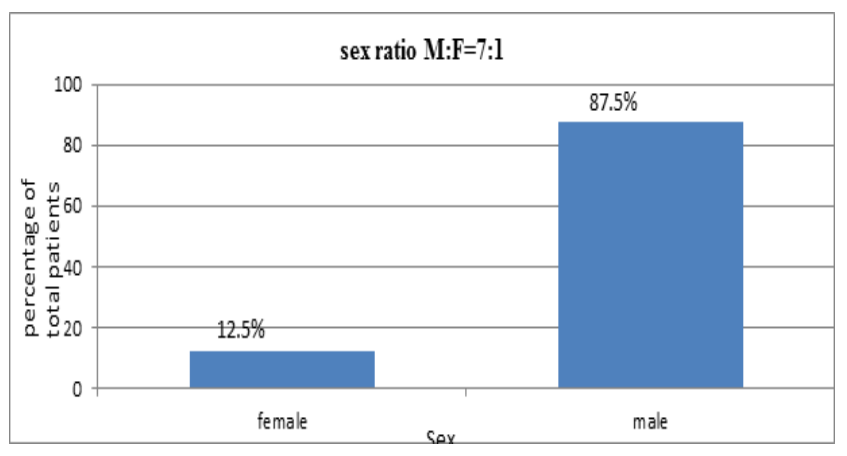

Fig 2: Gender

In this study, $35(87.5 \%)$ are males. This is because males are more exposed to high impact trauma.

\section{Side involved}

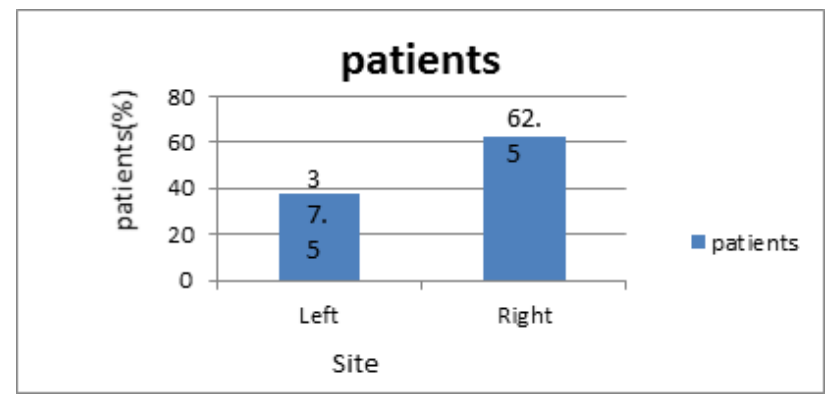

Fig 3: Side involved

In this study $15(37.5 \%)$ patients have fracture involving Left hand and $25(62.5 \%)$ patients have fracture involving right hand.

\section{Mode of Injury}

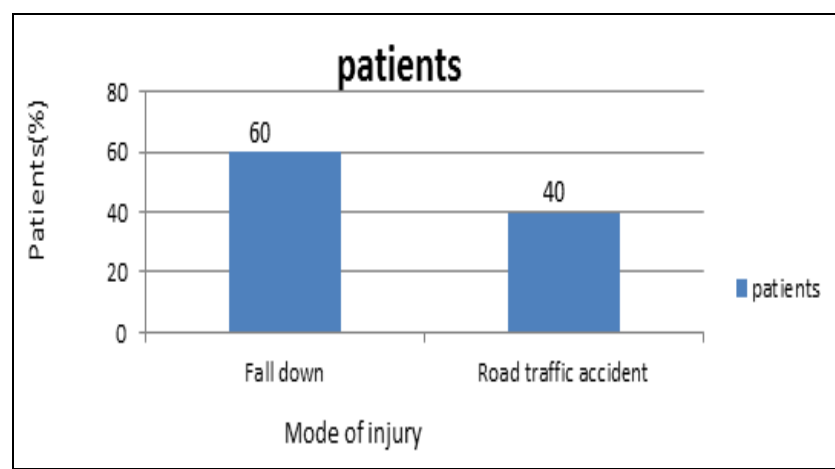

Fig 4: Mode

In our study $24(60 \%)$ patients had sustained a fracture due to a fall and $40 \%$ patients had road traffic accident. This is because of ever increasing number of high speed vehicles. 
5. Fracture documentation as per Frykman's ${ }^{7}$ classification

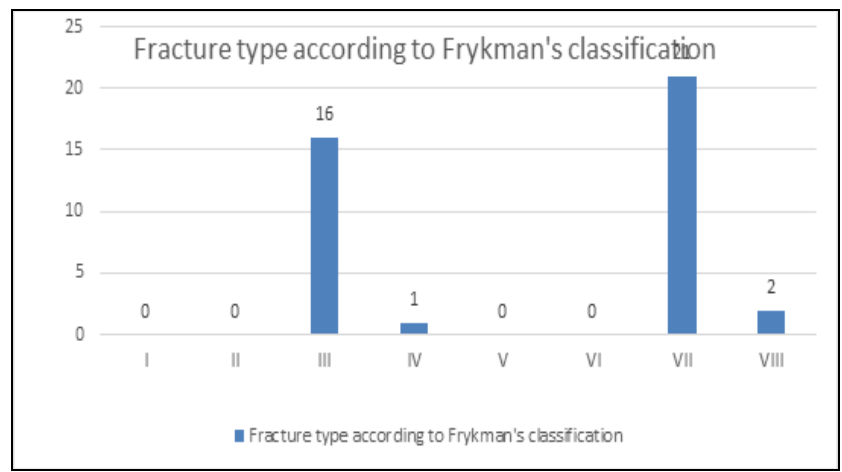

Fig 5: Fracture documentation according to Frykman's classification

In our study $16(40 \%)$ patients belong to type III, $1(2.5 \%)$ patient belongs to type IV, 21(52.5\%) patients belong to type VII, $2(5 \%)$ patients belong to type VIII. Since our study mainly includes intra articular and comminuted fractures the above distribution of fracture pattern was seen as other fractures were not included in the study.

\section{Movements at wrist joint at final follow up}

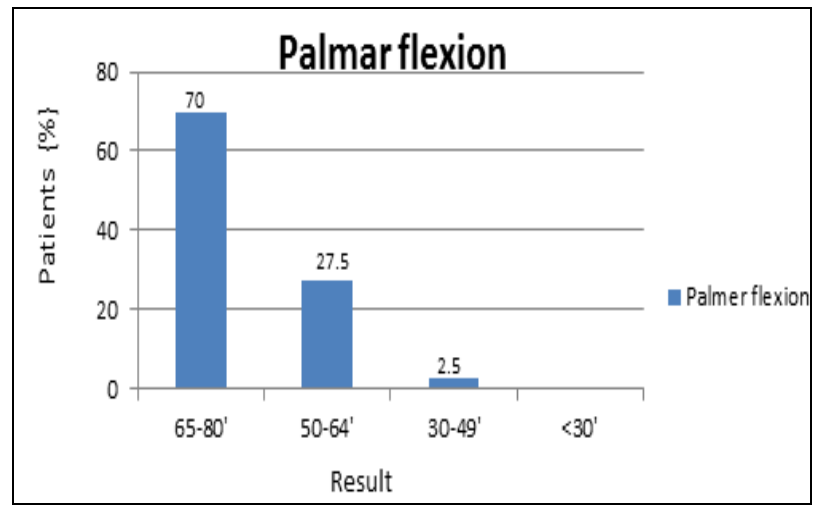

Fig 6: Palmar flexion

In our study, $28(70 \%)$ patients have achieved normal palmar flexion at wrist joint and $39(97.5 \%)$ patients have achieved functional palmar flexion. Mean palmar flexion was $70^{\circ}$.

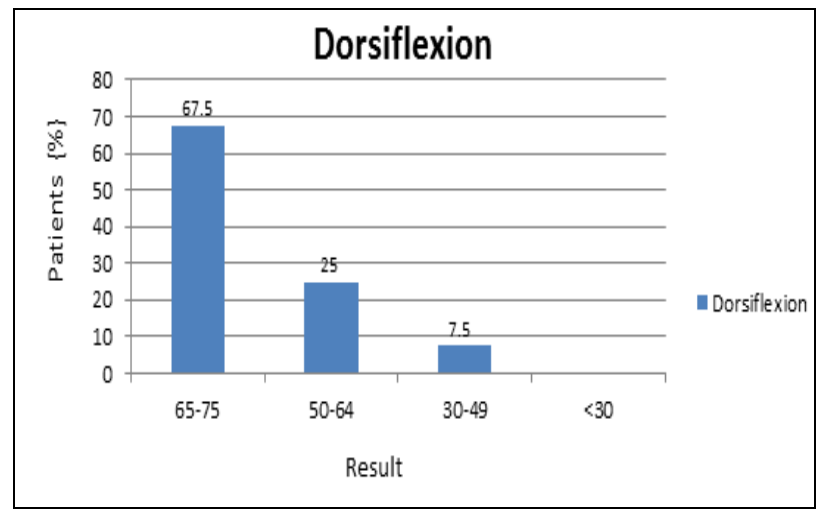

Fig 7: Dorsiflexion

In our study, $27(67 \%)$ patients have achieved normal dorsiflexion and $37(92.5 \%)$ patients have serviceable dorsiflexion. Mean dorsiflexion was $66^{\circ}$.

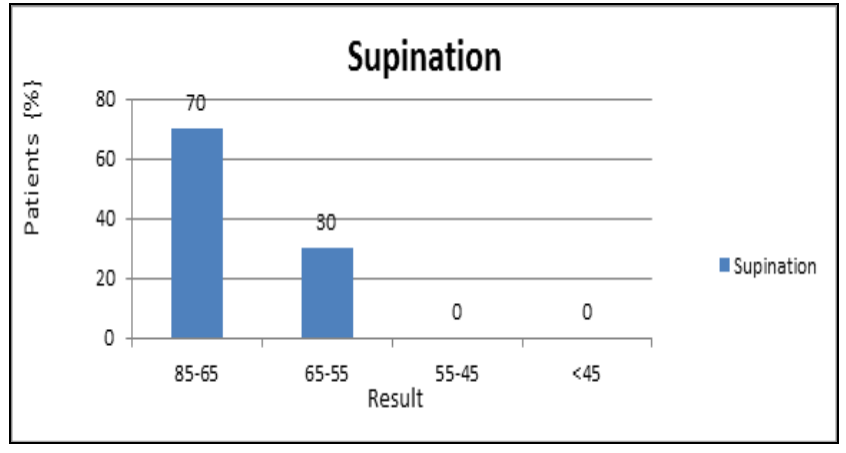

Fig 8: Supination

In our study $28(70 \%)$ patients have achieved normal supination and all patients achieved serviceable supination. Mean supination was $77^{\circ}$.

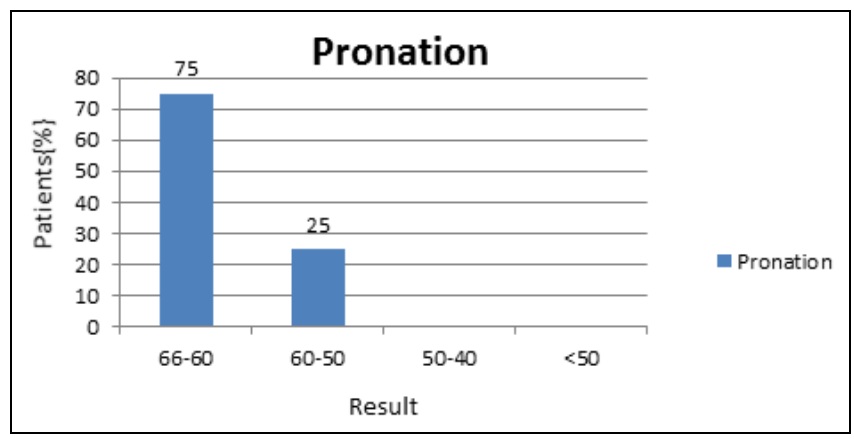

Fig 9: Pronation

In our study $30(75 \%)$ patients have achieved normal range of pronation all patients achieved serviceable range of motion. Mean pronation was $65^{\circ}$.

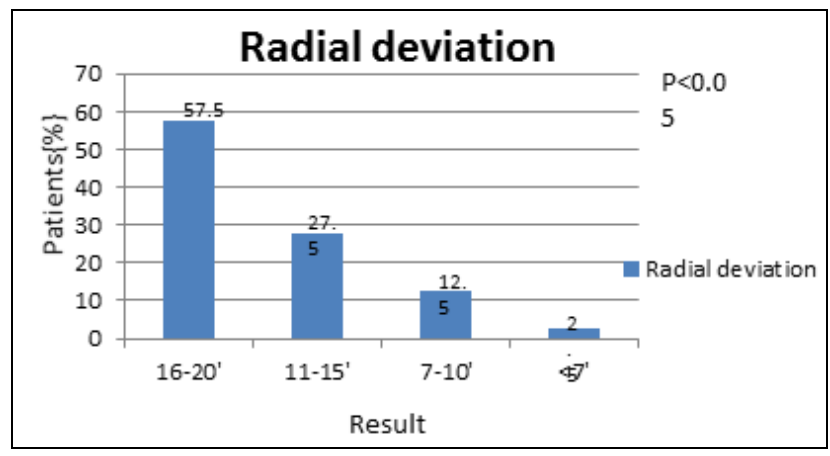

Fig 10: Radial deviation

In our study, $23(57.5 \%)$ patients have normal range of radial deviation and $34(85 \%)$ patients have serviceable radial deviation. Mean radial deviation was $14.5^{\circ}$.

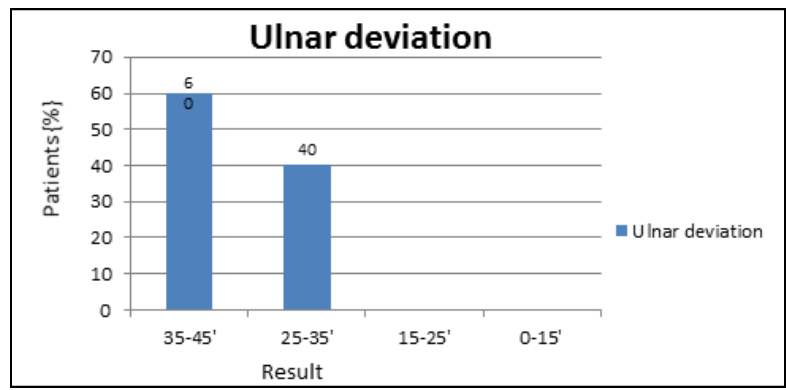

Fig 11: Ulnar deviation 
In this study, $24(60 \%)$ patiens have achieved normal range of ulnar deviation and all patients have achieved serviceable range of ulnar deviation. Mean ulnar deviation was $36^{\circ}$.

On the whole, more than $90 \%$ patients have serviceable range of movement. The slight restriction in dorsiflexion and palmer flexion could be due to hardware irritation.

\section{Radiological assessment}

1. Radial inclination

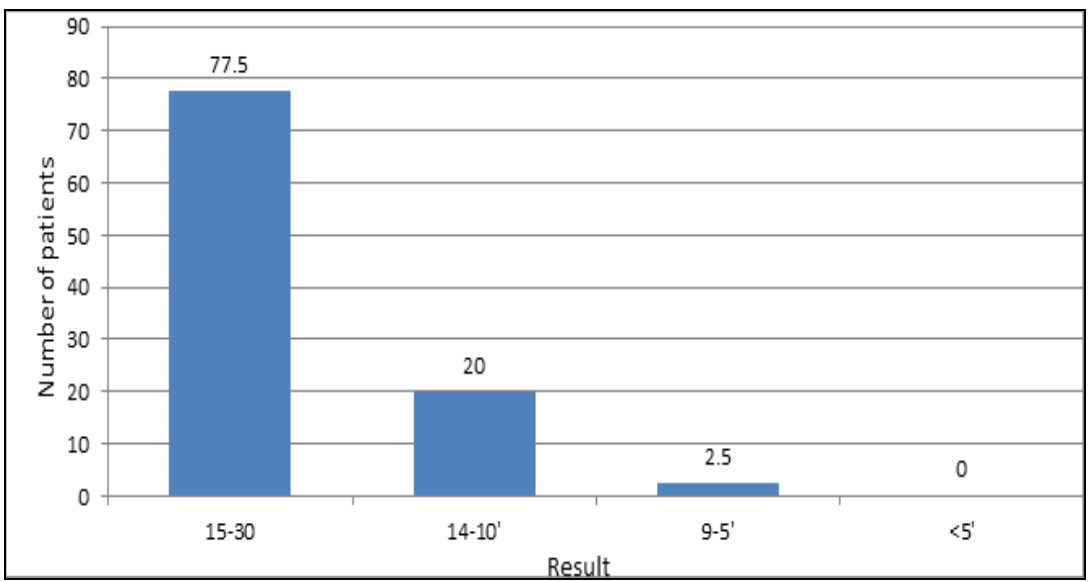

Fig 12: Mean radial inclination was $17^{\circ}$ which falls in the normal range of $13-30^{\circ}$.

\section{Radial length}

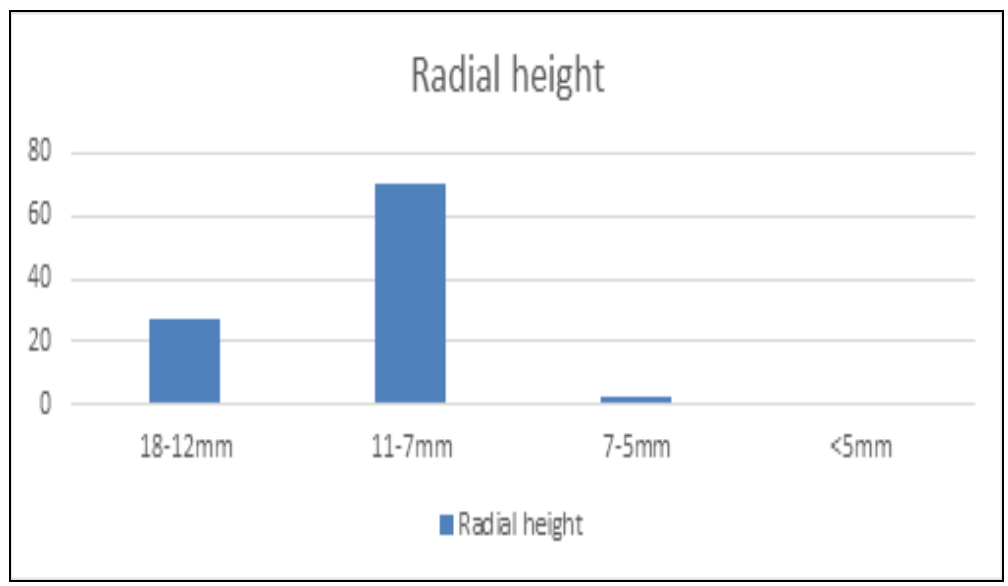

Fig 13

The average radial height was 10.85 which falls in the normal range of $8-18 \mathrm{~mm}$. But one patient had radial length $5 \mathrm{~mm}$ which fell beyond the normal range. This patient also has a residual dorsal tilt but his function was fair as per Gartland and Werley score.

\section{Palmer tilt}

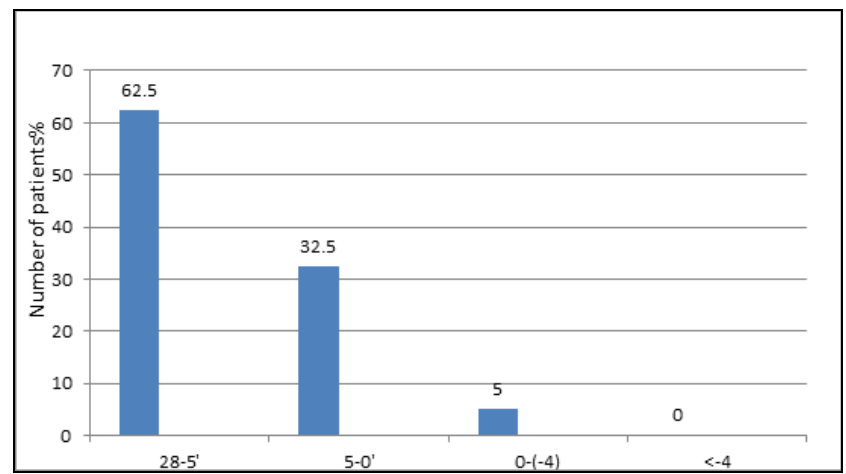

Fig 14
Mean palmar tilt was $9^{\circ}$ which falls in normal range of $0^{\circ}-28^{\circ}$. One patient had residual dorsal tilt.

\section{Operative Time}

In our study, 31(77.5\%) patients were operated within one hr. Thus if precisely done it is not a very time consuming procedure.

\section{Hospital Stay}

In our study, $35(87.5 \%)$ were discharged within one week. $12.5 \%$ of patients were discharged later due to pain and swelling.

\section{Functional Evaluation}

Table 1: Gartland and werley score and patient rated wrist evaluation score

\begin{tabular}{|c|c|c|}
\hline Gartland and werley score & Result & No. of Patients [\%] \\
\hline $0-02$ & Excellent & $29[72.50]$ \\
\hline $03-08$ & Good & $08[20.00]$ \\
\hline $09-20$ & Fair & $03[07.50]$ \\
\hline$>20$ & Poor & 00 \\
\hline
\end{tabular}


Table 2: Patient Rated Wrist Evaluation Score

\begin{tabular}{|c|c|c|}
\hline PRWE score [Patient Rated Wrist Evaluation Score] & Result & No. of Patients [\%] \\
\hline $0-25$ & Excellent & $29[72.50]$ \\
\hline $26-50$ & Good & $08[20.00]$ \\
\hline $51-75$ & Fair & $03[07.50]$ \\
\hline $76-100$ & Poor & 00 \\
\hline
\end{tabular}

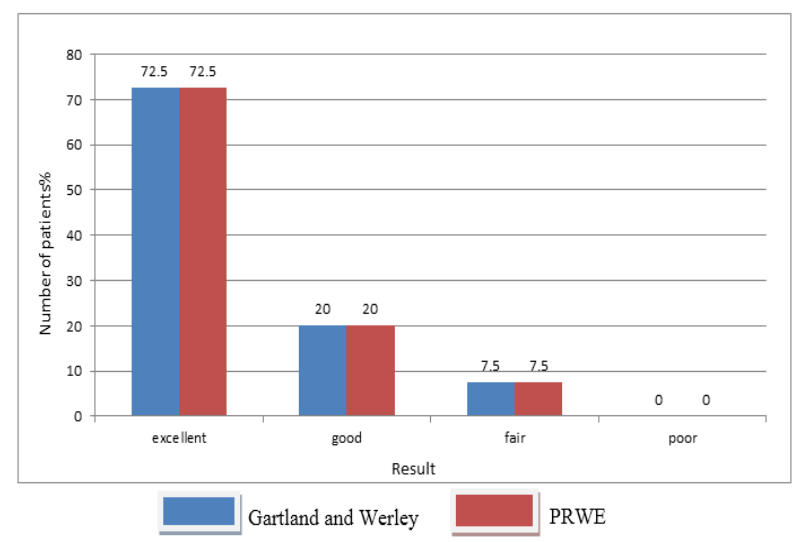

Fig 15

In our study, we have used two methods for functional evaluation. With either method $92.50 \%$ patients have found good to excellent results. Mean PRWE score was 21 and mean Gartland and Werley score was 3 .

\section{Results according to type of fracture}

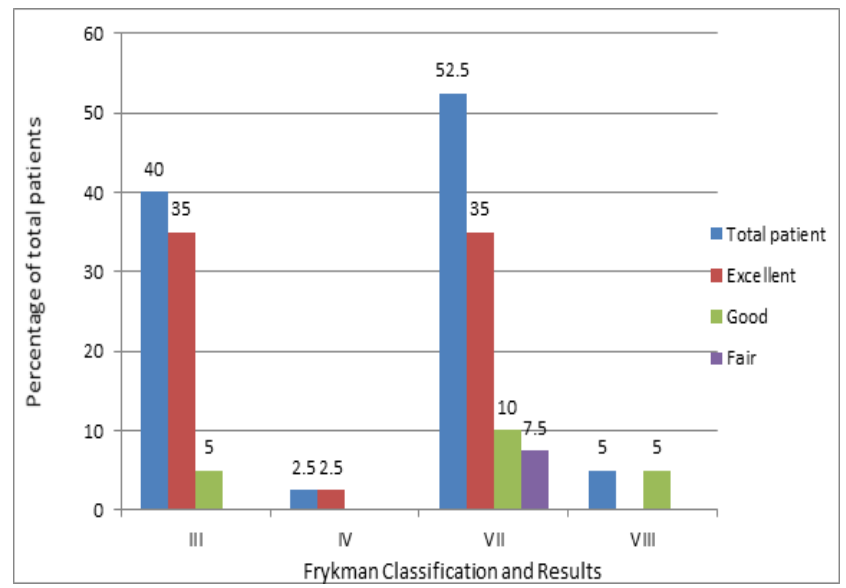

Fig 16

As per Frykman classification, out of 40 patients $40 \%$ patients are classified as type III, $2.5 \%$ patient are classified as type IV, $52.5 \%$ patients are classified as type VII, 5\% patients are classified as type VIII.

In type III $87.50 \%$ have excellent result and $12.50 \%$ have good result.

In type IV 100\% have good results.

In type VII $66.6 \%$ have excellent result and $19.04 \%$ have good result and $14.3 \%$ have fair result.

In type VIII 100\% have good results.

Type IV and Type VIII has one and two patients respectively. So their result is statistically not significant.

Most of our patients belong to Type III and Type VII. Our study shows nearly $90 \%$ good to excellent results in either group.

\section{Complications}

Table 3

\begin{tabular}{|c|c|}
\hline & No. of patients (\%) \\
\hline Residual dorsal tilt & $1(2.5 \%)$ \\
\hline Prominent Ulnar styloid & 0 \\
\hline Infection & 0 \\
\hline Radial deviation of hand & 0 \\
\hline Carpal tunnel syndrome & 0 \\
\hline Reflex sympathetic dystrophy & 0 \\
\hline Irritation/ rupture of tendons & 0 \\
\hline Non-Union & 0 \\
\hline
\end{tabular}

In our series, there was no infection and no neurovascular injury. One patient had residual dorsal tilt but the functional result was fair and it did not affect their day to day activities.

\section{Discussion}

Distal end radius fractures are common injuries around wrist in upper limb. Effective method for the fixation of distal radial fractures is demanding due to complex fractures patterns.

This is a study of 40 patients of distal end of radius fracture treated by volar plating. This study is essentially preliminary assessment. This study is only short term follow up with average of 6 months and a maximum follow up of two years. This study includes all patients with intraarticular distal end radius fracture.

Males are more affected then females and road traffic accident is found to be the most common cause of injury. The operating time in most of the patients was less than one hour. The average hospital stay was close to one week. Except for one patient with residual dorsal tilt, no other complications were reported in our series. All patients had sound union and only patient had residual dorsal tilt and radial shortening. More than $95 \%$ of patients had serviceable range of wrist movements

Table 4: Comparison of this study with other studies

\begin{tabular}{|c|c|c|}
\hline Criteria & Our study & E.Skouras $^{\mathbf{8}}$ \\
\hline Gartland and Werley Score & & \%patients \\
\hline Excellent & 72 & 64 \\
\hline Good & 20 & 30 \\
\hline Fair & 8 & 6 \\
\hline Poor & & \\
\hline
\end{tabular}

Table 5

\begin{tabular}{|c|c|c|}
\hline Criteria & Our study & RE Anakwe $^{\mathbf{9}}$ \\
\hline $\begin{array}{c}\text { Patient Related Wrist } \\
\text { Evaluation Score }\end{array}$ & (\% patients) & (\% patients) \\
\hline Excellent & 72.5 & 72 \\
\hline Good & 20 & 28 \\
\hline Fair & 7.5 & \\
\hline Poor & & \\
\hline
\end{tabular}

We have compared our functional results with two studies, one study (E.Skouras) using Gartland and Werley and second study (RE Anakwe) using Patient related wrist evaluation score. 
On comparison with E.Skouras study we observed that their good to excellent results were 94 and our good to excellent results were 92.5 which is comparable.

On comparison with RE Anakwe study it was found that they had $100 \%$ good to excellent results which is slightly better than our series. This could be because in our institute different surgeons operate which can modify final outcome of the patient

The functional outcome as assessed by Gartland and Werley score and PRWE score was $92 \%$ which is comparable with other studies.

\section{Conclusions}

Present study suggests that stabilizing the fracture fragments with volar plate and screws in the management of the fractures of distal radius, is an effective method to maintain reduction and prevent collapse of the fracture fragments. The technique emphasizes that open reduction and internal fixation with volar plating has excellent functional outcome with minimal complications.

Hence volar approach and locking plate should be the prefered implant for treatment of intra articular (volar barton), unstable, comminuted fractures of distal end radius.

\section{References}

1. Rockwood, Green's Fracture in adults, Distal end radius fractures epidemiology $8^{\text {th }}$ edition. 1(32):1059.

2. Epidemeology of fractures, Kate w. Nellas, Evan Kowalski, Kevin C. Chung, PMC, Hand Clin May. 2012; 28(2):113-125.

3. Colles A. On the fracture of the carpal extremity of the radius. Edinburgh Med Surg. 1814; 10:182-6.

4. Outcome of fracture distal end of radius in adults treated by open reduction and internal fixation with buttress plate, Pattanashetty OB, Shushrut Bhavi, Monish Bami, Deepesh Daultani, Yogesh Mapari, Kerala Journal Of Orthopaedics. 2013, 26(2).

5. Gartland Jj Jr, Werley Cw. Evaluation Of Healed Colles' Fractures. J Bone Joint Surg Am. 1951; 33:895-907.

6. Mac Dermaid JC, Turgeon T, Richards RS, Beadle M, Roth JH. Patient rating of wrist pain and disability: a reliable and valid measurement tool. J Orthop Trauma. 1998; 12:77-86.

7. Frykman GK. Fracture of the distal radius including sequelae shoulder hand finger syndrome. Disturbance in the distal radioulnar joint and impairment of nerve function. A clinical and experimental study. Acta Orthop Scand Suppl. 1967; 108:1-155.

8. Operative treatment and outcome of unstable distal radial fractures using a palmar T-miniplate at a non-specialized institution. Skouras YE. Hosseini V. Berger K. Wegemann, TC Koslowsky V Strat Traum Limb Recon. 2013; 8:155-160.

9. Locked volar plating for complex distal radius fractures: Patient outcomes and satisfaction. RE Anakwe, LAK Khan, RE Cook, JE McEachan. Anakwe et al. Journal of orthopaedic Surgery and research. 2010; 5:51. 